\title{
A new perturb and observe MPPT algorithm based on two steps variable voltage control
}

\author{
Hussain Attia ${ }^{1}$, Suleyman Ulusoy ${ }^{2}$ \\ ${ }^{1}$ Department of Electrical, Electronics and Communications Engineering, American University of Ras Al Khaimah, UEA \\ ${ }^{2}$ Department of Mathematics and Natural Sciences, American University of Ras Al Khaimah, UEA
}

\section{Article Info \\ Article history: \\ Received Jun 11, 2021 \\ Revised Sep 22, 2021 \\ Accepted Sep 29, 2021}

\section{Keywords:}

Conventional perturb

DC-DC boost converter

MATLAB/Simulink

Duty cycle

Observe algorithm two step

control

Observe algorithm two steps

perturb

\begin{abstract}
Based on the fact that the effectiveness of perturb and observe algorithm in a maximum power point tracking maximum power point tracking (MPPT) in a photovoltaic array is a tradeoff between the tracking speed during the transient response and the oscillation around the stable level during the steady state response. To have a high tracking speed, incremental step should be high, but this high incremental step increases the oscillation level around the steady level of MPPT, whereas adopting low incremental step reduces the algorithm response time but improve the response during the steady state condition. This paper presents a new perturb and observe algorithm based on two step variable control for MPPT applications. A two variable incremental step control is proposed to gain the merit of high step for guaranteeing a fast response during tracking process, and also for guaranteeing the merit of low oscillation during the steady state working condition through adopting a low step during steady state response. The effectiveness of the proposal is proved by the analysis of the simulation results via MATLAB/Simulink software, and by the comparison of the simulation results with a conventional perturb and observe MPPT algorithm.
\end{abstract}

This is an open access article under the CC BY-SA license.

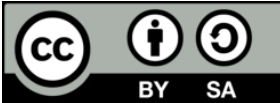

\section{Corresponding Author:}

Hussain Attia

Department of Electrical, Electronics and Communication Engineering

American University of Ras Al Khaimah

Ras Al Khaimah, 10021, UAE

Email: hattia@aurak.ac.ae

\section{NOMENCLATURE}

$I_{P V} \quad$ : $\quad$ PV cell output current (A)

$I_{S C} \quad$ : Light generated current $(\mathrm{A})$

$I_{D} \quad$ : Diode current (A)

$I_{s h} \quad$ : Shunt current (A)

$V_{D} \quad: \quad$ Diode Voltage $(\mathrm{V})$

$V_{T} \quad$ : Temperature voltage $(\mathrm{V})$

$I_{o} \quad: \quad$ Diode saturation current (A)

$V_{P V}:$ PV cell output voltage $(\mathrm{V})$

$D$ : Duty cycle of DC-DC converter

$\varepsilon \quad$ : A small absolute $\Delta P / \Delta V$

$\begin{array}{lll}R_{s} & : & \text { PV cell series resistor }(\Omega) \\ R_{s h} & : & \text { PV cell shunt resistor }(\Omega) \\ N_{s} & : & \text { No. of PV cells in series } \\ N_{s h} & : & \text { No. of PV cells in parallel } \\ V_{P V-T o t} & : & \text { Total output voltage from a PV module } \\ I_{P V-T o t} & : & \text { Total output current from a PV module } \\ \Delta V & : & \text { Voltage difference } V(t)-V(t-\Delta t) \\ \Delta P & : & \text { Power difference } P(t)-P(t-\Delta t) \\ V_{\text {step }} & : & \text { An increment/decrement in tracking voltage }\end{array}$

$R_{s} \quad: \quad$ PV cell series resistor $(\Omega)$

$V_{P V-T o t}:$ Total output Voltage from a PV module

$\Delta P \quad: \quad$ Power difference $P(t)-P(t-\Delta t)$ 


\section{INTRODUCTION}

Solar renewable energy is representing as a valuable source of direct current electrical power due to its availability everywhere, cleanness without any polluted emission, and without any cost of producing. A photovoltaic (PV) panel absorbs the solar energy and converts the sunlight into electricity when it's either working within a standalone PV system or within grid connected system [1], [2].

The desired output voltage and/or output current or power can be obtained through a specific design of the PV array. In other words, the way of PV panels' arrangement in the system PV array will affect the level of output voltage and output current [3]. To increase the level of output voltage from the PV array, the number of serially connected panels in the branches of PV array should be increased. Whereas to increase the level of output current from the PV array, the number of parallel branches should be increased [4], [5].

Many research studies in standalone or in grid connected photovoltaic systems design and implementation have been focused on increasing the quantity of harvested solar energy through considering the characteristics of solar PV panels, and how the generated electricity from the panel is nonlinearly affected by the light intensity and ambient temperature [6]-[8]. Based on these characteristics, there is an opportunity to let a PV panel work in the area front of the sunlight during working day hours to harvest the maximum power through an electromechanically tracking system [9]. Different algorithms have been proposed to guarantee the maximum power point tracking (MPPT) working condition, and each algorithm has different process to reach to the MPP point with different specifications or merits [10]-[21].

In [10]-[12], many algorithms for MPPT objective have been proposed, such as incremental conductance (IC) algorithm, Perturb and Observe (PandO) algorithm, open voltage method, and short circuit current method. All of the mentioned algorithms were characterized by simplicity and negatively affected response by the algorithm process. For higher robustness performance, fuzzy logic control (FLC) has proposed in [13], in which, the FLC have inserted to support the Hill-Climbing algorithm in tracking the MPP foe PV system applications. For fast and accurate response of MPPT function, FLC has been included in a certain PV systems design in [14]. Other studies have focused on a high stability performance in the MPPT function based on FLC, which were shown in [15]-[18]. All the research studies based on FLC reflect difficulties in designing the steps, blocks, memberships' rules of FLC, leading to an addition of a demerit to applying the FLC in PV systems.

Recently, artificial neural networks (ANN) algorithms have proposed as Machine learning algorithms in [19]-[22] for fast tracking the MPP during different weather conditions. ANN algorithm demonstrates fast and accurate response, but at the same time, it needs a fast and complicated processor to execute the internal calculations.

The remaining of this paper is organized as shown: The process and steps of conventional PandO algorithm for MPPT objective are shown in Section 2. The proposed modified PandO algorithm with all differences with respect to the conventional one is demonstrated in Section 3. Proving the merits of the proposed modified algorithm is shown in Section 4 using MATLAB/Simulink simulation program. The findings of this study are summarized and concluded in Section 5.

\section{CONVENTIONAL PERTURB AND OBSERVE (PO) ALGORITHM}

The methodology of this algorithm is to consider the behavior of photovoltaic module/panel with respect to the weather condition variations, namely light intensity and ambient temperature:

\subsection{Solar photovoltaic representation}

The solar cell has non-linear behavior of the output current and power with respect to output voltage variation based on the instantaneous weather conditions. The output power is positively affected by the level of irradiance or light intensity, whereas it is negatively affected by the level of ambient temperature [22]-[24]. The equivalent electrical circuit which represents the photovoltaic cell is shown in Figure 1. The level of drop voltage in the cell is proportional to the value of series resistance $R_{s}$. The current $I_{P V}$ passing through the series resistor can be determined by subtracting the shunt current $I_{s h}$ which is passing through the shunt resistor $R_{s h}$ and the diode current $I_{D}$ from the light-generated current $I_{s c}$. The total output voltage from the PV module $V_{P V-T o t}$ can be represented by the product of the output voltage of one PV cell $V_{P V}$ and the number of serially connected PV cells $N_{s}$, whereas the total output current from the PV module $I_{P V \text {-Tot }}$ can be represented by the product of the output current from one PV cell $I_{P V}$ and the number of parallel connected PV cells $N_{s h}$ as shown in the related relationships (1) to (6) [22]-[24].

$$
I_{P V}=I_{S C}-I_{D}-I_{S h}
$$




$$
\begin{aligned}
& I_{D}=I_{o}\left\{e^{\frac{V_{D}}{V_{T}}}-1\right\} \\
& I_{S h}=\frac{V_{D}}{R_{S h}} \\
& V_{P V}=V_{D}-R_{S} I_{P V} \\
& V_{P V-T o t}=V_{P V} \times N_{S} \\
& I_{P V-T o t}=I_{P V} \times N_{S h}
\end{aligned}
$$

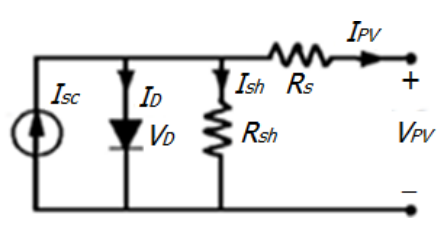

Figure 1. A photovoltaic cell circuits

The solar photovoltaic panel module 1Soltech $1 \mathrm{STH}-215-\mathrm{P}$ is selected to demonstrate the participation of this study. The electrical characteristics of the selected PV module are shown in Table 1, whereas Figure 2 shows the curves of the output current and power from the PV module for different levels of irradiance (light intensity) $200 \mathrm{~W} / \mathrm{m}^{2}, 400 \mathrm{~W} / \mathrm{m}^{2}, 600 \mathrm{~W} / \mathrm{m}^{2}, 800 \mathrm{~W} / \mathrm{m}^{2}$, and $1000 \mathrm{~W} / \mathrm{m}^{2}$ all at a constant ambient temperature $25{ }^{\circ} \mathrm{C}$. The positive proportion of the output current and produced power with respect to the light intensity are clearly demonstrated.
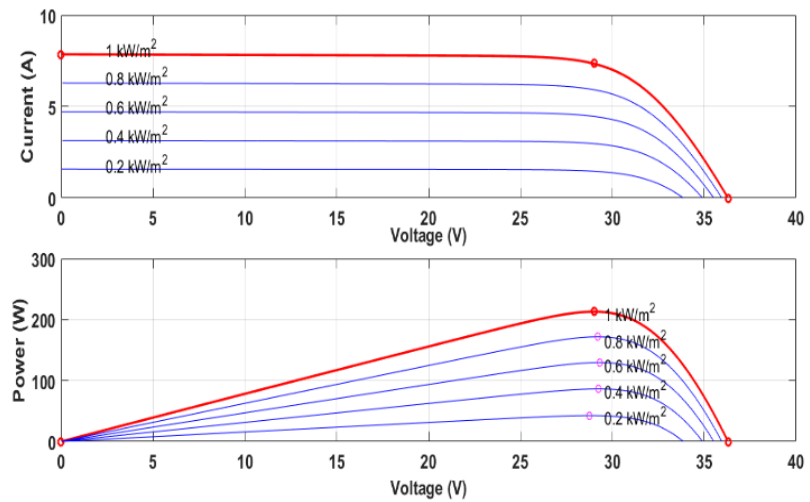

Figure 2. The curves of the output current and power from the PV module
Table 1. Specifications of the PV MODULE: 1Soltech 1STH-215-P

\begin{tabular}{lc}
\hline \multicolumn{1}{c}{ PV panel Parameter } & VALUE \\
\hline Maximum power & $213.15 \mathrm{~W}$ \\
Voltage at MPP & $29 \mathrm{~V}$ \\
Current at MPP & $7.35 \mathrm{~A}$ \\
Open circuit voltage $V_{o c}$ & $36.3 \mathrm{~V}$ \\
Short circuit current $I_{s c}$ & $7.84 \mathrm{~A}$ \\
Temperature coefficient of & $-0.36099 \mathrm{~V}$ \\
$V_{o c}(\% /$ deg.C) & \\
Temperature coefficient of & $0.102 \mathrm{~A}$ \\
$I_{s c}(\% /$ deg.C) & \\
Number of cells per & 60 \\
module (Ncell) & \\
Light-generated current $I_{s c}$ & $7.8649 \mathrm{~A}$ \\
Diode saturation current Io & $2.9259 \mathrm{e}-10 \mathrm{~A}$ \\
Shunt resistance $R_{s h}$ & $313.3991 \Omega$ \\
Series resistance $R_{s}$ & $0.39383 \Omega$ \\
\hline
\end{tabular}

\subsection{The process of conventional PandO algorithm}

The behavior of the output power of the PV panel with respect to the output voltage is shown in Figure 3, in which the maximum power point MPP is located in the point of no change in output power during the change in output voltage [25]-[27]:

$$
\frac{\Delta P}{\Delta V}=0
$$

The PandO algorithm considers this fact in the process of searching to the accurate value of the output voltage at MPP. The process of the algorithm is started, as shown in Figure 4 of the algorithm flowchart, by measuring the instantaneous values of the PV panel output voltage $V(t)$ and current $I(t)$ as present data, and repeats measuring PV voltage and current after a certain sample period to have $V(t), V(t-\Delta t)$, $I(t)$, and $I(t-\Delta t)$. The second step is instantaneous values of the current output power $P(t)$, and the previous power sample value $P(t-\Delta t)$, in addition to calculate the difference in output voltage $\Delta V$, and the difference in output power $\triangle P$ :

A new perturb and observe MPPT algorithm based on two steps variable voltage control (Hussain Attia) 


$$
\begin{aligned}
& \mathrm{P}(\mathrm{t})=\mathrm{V}(\mathrm{t}) \times \mathrm{I}(\mathrm{t}) \\
& \mathrm{P}(\mathrm{t}-\Delta \mathrm{t})=\mathrm{V}(\mathrm{t}-\Delta \mathrm{t}) \times \mathrm{I}(\mathrm{t}-\Delta \mathrm{t}) \\
& \Delta \mathrm{V}=\mathrm{V}(\mathrm{t})-\mathrm{V}(\mathrm{t}-\Delta \mathrm{t}) \\
& \Delta \mathrm{V}=\mathrm{V}(\mathrm{t})-\mathrm{V}(\mathrm{t}-\Delta \mathrm{t})
\end{aligned}
$$

Then the searching process of the algorithm works on giving an addition or subtraction of a certain constant voltage step based on the instantaneous measurement of the PV panel output current and voltage and based on comparison decisions. In spite of the simplicity of the conventional algorithm, the demerits of the constant voltage step MPP searching method of the conventional PandO algorithm are representing by that it needs to have a high voltage step to guarantee fast response from the algorithm. On the other side, if considering a high voltage step, this leads to have a high level of oscillation during steady state weather conditions [25]-[27].

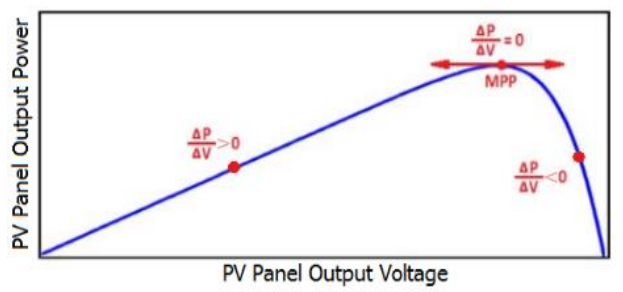

Figure 3. The output power curve with respect to output voltage and MPP point of the PV module

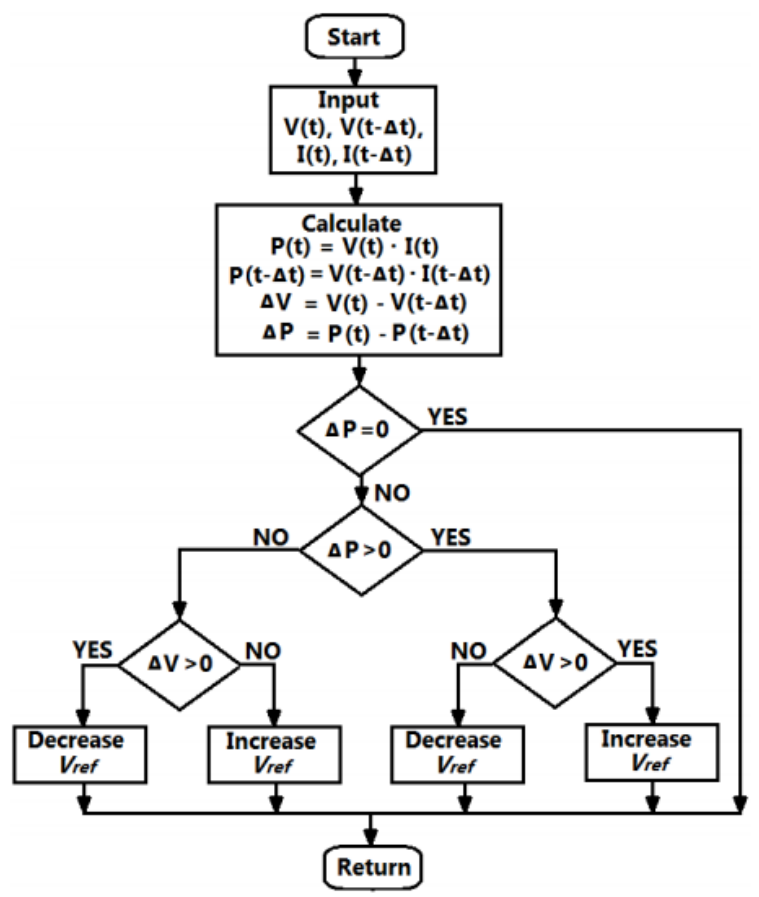

Figure 4. The flowchart of the conventional PandO algorithm

\section{PROPOSED PandO ALGORITHM BASED ON TWO STEPS VOLTAGE CONTROL}

The demerits of the constant voltage step in terms of the difficulty are guaranteeing a fast response using a high voltage step, because this leads to have a high level of oscillation at a steady state weather condition. For the objective of avoiding these demerits, this study proposes a two-voltage step control based on continuous measurement of the power difference between power samples. Figure 5 shows the flowchart of 
the proposed enhanced PandO algorithm including the two voltage steps control. The proposed variable control adopts two voltage steps for increment, the high voltage step is used during tracking the MPP when the difference in output power $\Delta P$ is high or more than a certain limit like $\varepsilon$ as shown in Figure 3 , and in the proposed flowchart of Figure 5. In other words, if $|\Delta P|>\varepsilon$, where $\varepsilon$ is a small limited change in the power difference between two successive power samples, the algorithm will adopt a high voltage step whereas if $|\Delta P|<\varepsilon$ it adopts a low voltage step.

By this proposed process, the enhanced PandO algorithm guarantees the fast response during the dynamic condition by considering a high step voltage, whereas it guarantees a small oscillation during the steady weather conditions by considering a low step voltage.

For $i=1,2 \ldots$; When The process will select a high voltage step, whereas when the process will replace the full voltage step by the one tenth voltage step $0.1 \times V$ step, which is suitable for low level of $\Delta P$.

$$
\begin{aligned}
& \left|\frac{\Delta \mathrm{P}_{i}}{\Delta V}\right|>\varepsilon \\
& \left|\frac{\Delta \mathrm{P}_{i}}{\Delta V}\right|>\varepsilon
\end{aligned}
$$

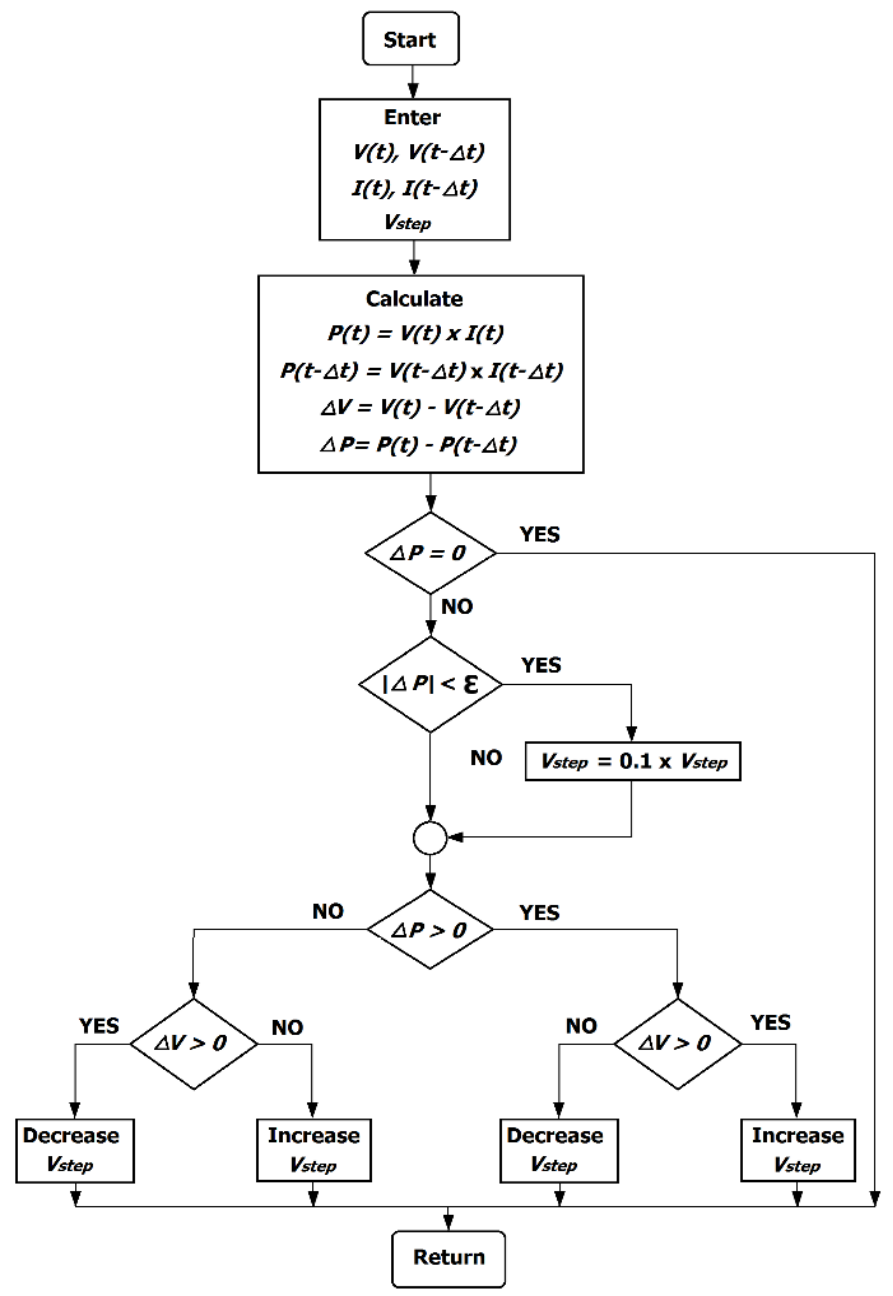

Figure 5. Flowchart of the proposed enhanced PandO algorithm

\section{COMPARATIVE ANALYSIS OF SIMULATION RESULTS}

The proposed enhance PandO algorithm is evaluated through doing a performance comparative analysis with the conventional PandO algorithm using MATLAB/Simulink. The DC-DC boost converter is designed based on design steps of [7], the converted is controlling by control the instantaneous value of duty cycle $D$, Table 2 shows the converter designed parameters. The simulated photovoltaic PV system adopts one

A new perturb and observe MPPT algorithm based on two steps variable voltage control (Hussain Attia) 
PV panel module 1Soltech 1STH-215-P, which is connected with the DC-DC converter. For MPPT purpose, the duty cycle of the converter is, firstly, controlled using the conventional PandO algorithm process with a high voltage step to demonstrate the negative effect of adopting a constant high step voltage. After that the process of the convention algorithm is repeated with a low voltage step to demonstrate the negative effect of a constant low step voltage.

Figure 6 shows the performance of the MPPT PV system controlled by a high voltage step conventional PandO algorithm. Figure 6 (a) shows the selected regular five period during 1.25 seconds of different irradiance levels $\left(400 \mathrm{~W} / \mathrm{m}^{2}, 600 \mathrm{~W} / \mathrm{m}^{2}, 800 \mathrm{~W} / \mathrm{m}^{2}, 1000 \mathrm{~W} / \mathrm{m}^{2}\right.$, and $\left.700 \mathrm{~W} / \mathrm{m}^{2}\right)$. Figure 6 (b) shows the duty cycle variation during these five periods. It is clearly noted that a high fluctuation in the instantaneous level of duty cycle when a high step voltage is used, at the same time it has fast tracking during the irradiance levels variation. Figure 6 (c) confirms the matching between the variation in the output power levels with respect to the variation in the duty cycle demonstrating the fast response and high-power fluctuation at the same time.

Figure 7 shows the system performance controlled by a low voltage step through a conventional PandO algorithm. Figure 7 (b) shows the duty cycle variation during these five periods. It is clearly noted that there is a low fluctuation in the instantaneous level of duty cycle as well as the slow response in MPP tracking during the variation in irradiance levels. Figure 7 (c) demonstrates the output power variation with low fluctuation during steady weather conditions, at the same time it reflects the slow response during the variation in irradiance levels.

Figure 8 shows the performance of the proposed enhanced PandO algorithm, which adopts two steps voltage control. High step voltage for fast response during dynamic weather conditions, whereas low step voltage for low oscillation during the steady weather conditions.

Figure 8 (b) shows the duty cycle response which demonstrates the fast response for MPP tracking and low oscillation for the weather steady conditions as marked by black color ovals. Figure 8 (c) demonstrates and confirms the merits of the proposed enhanced algorithm in terms of delivered power. The enhancements are represented by fast tracking and low oscillation during steady weather conditions.

Table 2. Parameters of the designed DC-DC boost converter

\begin{tabular}{cc}
\hline Parameter & VALUE \\
\hline Load resistor & $20 \Omega$ \\
Input capacitor & $100 \mu \mathrm{F}$ \\
Converter inductor & $2 \mathrm{mH}$ \\
Output capacitor & $100 \mu \mathrm{F}$ \\
Switching frequency $f_{s}$ & $10 \mathrm{kHz}$ \\
\hline
\end{tabular}

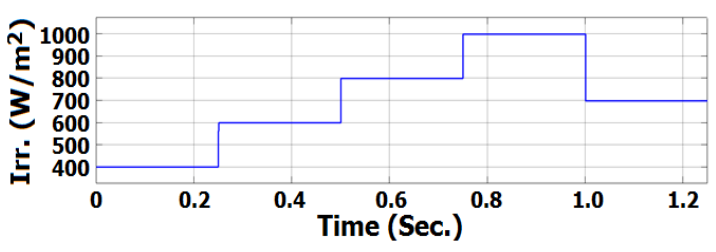

(a)

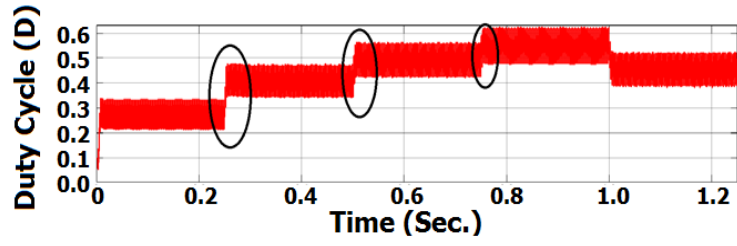

(b)

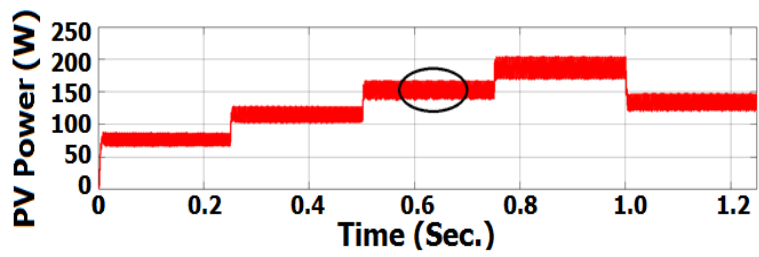

(c)

Figure 6. PV system performance using a conventional PandO algorithm with high step voltage, (a) five equally periods of different irradiance, (b) duty cycle response, (c) output power response 


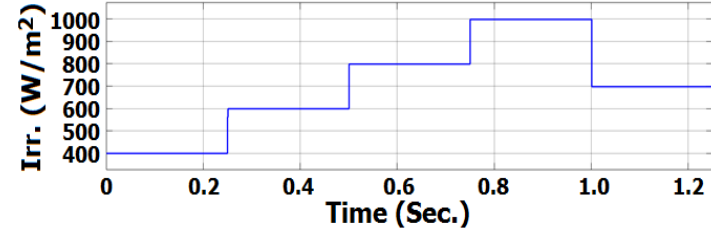

(a)

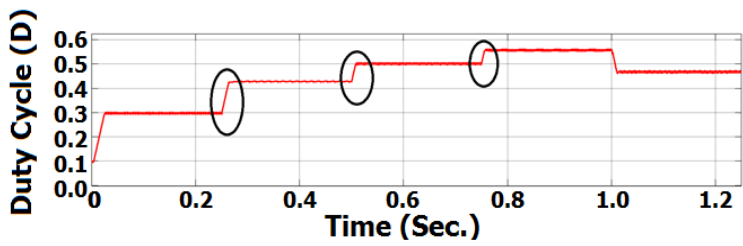

(b)

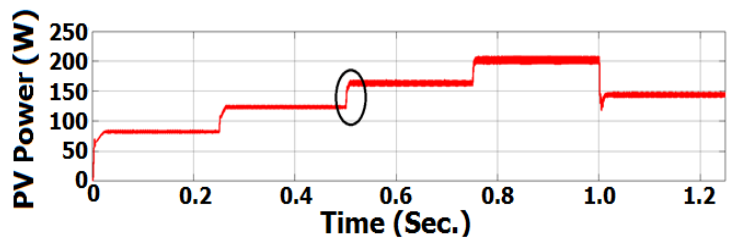

(c)

Figure 7. PV system performance using a conventional PandO algorithm with low step voltage, (a) five equally periods of different irradiance, (b) duty cycle response, (c) output power response

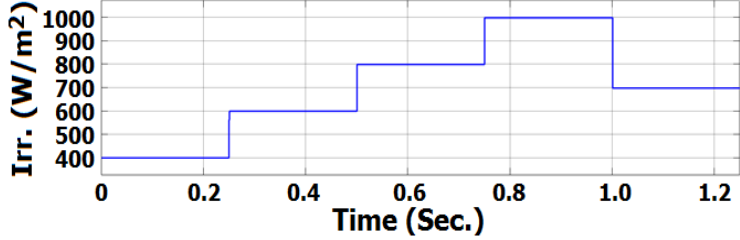

(a)

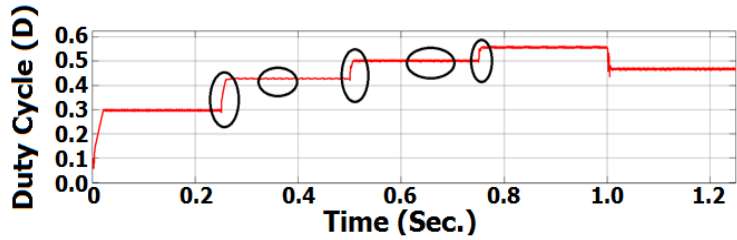

(b)

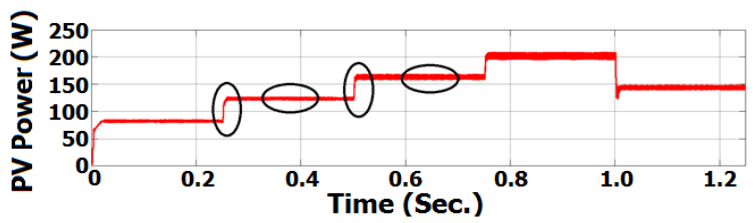

(c)

Figure 8. PV system performance using the proposed enhanced PandO algorithm with variable step voltage, (a) five equally periods of different irradiance, (b) duty cycle response, (c) output power response

\section{CONCLUSION}

A new enhanced PandO algorithm compared to the conventional a PandO algorithm has been proposed in this study by two steps voltage variable control to integrate the performance of the photovoltaic MPPT system. The proposed algorithm avoids the demerits of the conventional PandO algorithm which is represented by the tradeoff between the fast MPP tracking during the dynamic response and the low oscillation during the steady weather conditions. Proposing two steps voltage control guarantees the fasttracking response, and at the same time guarantees the low oscillation in the output power performance during the steady state work conditions. The performance of the proposed solution is evaluated through a comparative analysis with the conventional PandO algorithm using MATLAB/Simulink.

\section{ACKNOWLEDGEMENTS}

The authors appreciate the financial support provided by office of research and community service, American University of Ras Al Khaimah-UAE, https://aurak.ac.ae/en/academics/office-of-research-communityservice/

\section{REFERENCES}

[1] H. A. Attia, T. K. S. Freddy, H. S. Che, W. P. Hew and A. H. El Khateb, "Confined Band Variable Switching Frequency Pulse Width Modulation (CB-VSF PWM) for a Single-Phase Inverter with an LCL Filter," in IEEE Transactions on Power Electronics, vol. 32, no. 11, pp. 8593-8605, Nov. 2017, doi: 10.1109/TPEL.2016.2645739.

[2] S. Alsadi, and B. Alsayid, "Maximum Power Point Tracking Simulation for Photovoltaic Systems Using Perturb and Observe Algorithm," International Journal of Engineering and Innovative Technology (IJEIT), vol. 2, Iss. 6, pp. 80-85, 2012.

[3] N. Onat, "Recent Developments in Maximum Power Point Tracking Technologies for Photovoltaic Systems," International Journal of Photoenergy, vol. 2010, doi:10.1155/2010/245316.

[4] H. Attia, and K. Hossin, "Integrated Renewable PV System through Artificial Neural Network Based MPPT and Water Cooling Treatment," 2019 International Conference on Electrical and Computing Technologies and Applications (ICECTA), 2019, pp. 1-5, doi: 10.1109/ICECTA48151.2019.8959581. 
[5] J.-S. Ko, J.-H. Huh, and J.-C. Kim," Overview of Maximum Power Point Tracking Methods for PV System in Micro Grid", Electronics 2020, 9, 816; doi:10.3390/electronics9050816.

[6] H. Attia, M. Mohsen, B. Qadoor, M. Al Shamsi, O. Abdulsalam, and Z. Rahman, "New Design and Implementation of a Solar Car of the American University of Ras Al Khaimah: Electrical Vision," Journal of Sustainable Development of Energy, Waterand Environment Systems, vol. 8, no. 3, pp. 452-463, 2020, doi: 10.13044/j.sdewes.d7.0281.

[7] H. A. Attia, Y. I. Al-Mashhadany, and B. N. Getu, "Design and Simulation of a High Performance Standalone Photovoltaic System," ICREGA'14 - Renewable Energy: Generation and Applications, pp. 683-697, 2014, doi: 10.1007/978-3-319-05708-8_56.

[8] M. A. Abdourraziq and M. Maaroufi, "Experimental Verification of the Main MPPT Techniques for Photovoltaic System," International Journal of Power Electronics and Drive Systems, vol. 8, no. 1, pp. 384-391, March 2017, doi: 10.11591/ijpeds.v8.i1.pp384-391.

[9] T. Thakur and K. S. Bedi, "Data based MPPT technique for photovoltaic system," 2011 Annual IEEE India Conference, 2011, pp. 1-5, doi: 10.1109/INDCON.2011.6139511.

[10] H. A. Sher, A. F. Murtaza, A. Noman, K. E. Addoweesh, and M. Chiaberge, "An intelligent control strategy of fractional short circuit current maximum power point tracking technique for photovoltaic applications," Journal of Renewable and Sustainable Energy, vol. 7, no. 1, p. 013114, 2015, doi: 10.1063/1.4906982.

[11] B. N. Alajmi, K. H. Ahmed, S. J. Finney and B. W. Williams, "Fuzzy-Logic-Control Approach of a Modified Hill-Climbing Method for Maximum Power Point in Microgrid Standalone Photovoltaic System," in IEEE Transactions on Power Electronics, vol. 26, no. 4, pp. 1022-1030, April 2011, doi: 10.1109/TPEL.2010.2090903.

[12] Subiyanto, A. Mohamed and M. A. Hannan, "Maximum power point tracking in grid connected PV system using a novel fuzzy logic controller," 2009 IEEE Student Conference on Research and Development (SCOReD), 2009, pp.349-352, doi: 10.1109/SCORED.2009.5443002.

[13] A. El Khateb, N. A. Rahim, J. Selvaraj and M. N. Uddin, "Fuzzy-Logic-Controller-Based SEPIC Converter for Maximum Power Point Tracking," in IEEE Transactions on Industry Applications, vol. 50, no. 4, pp. 2349-2358, July-Aug. 2014, doi: 10.1109/TIA.2014.2298558.

[14] H. El Khateba, N. Abd Rahima, and J. Selvaraja, "Fuzzy logic control approach of a maximum power point employing SEPIC converter for standalone photovoltaic system," Procedia Environmental Sciences, vol. 17, pp. 529-536, 2013, doi: 10.1016/j.proenv.2013.02.068

[15] R. Samuel Rajesh Babu, "A Comparative Analysis of Integrated Boost Flyback Converterusing PID and Fuzzy Controller," International Journal of Power Electronics and Drive Systems (IJPEDS), vol. 5, no. 4, pp. 486-501, 2015, doi: 10.11591/ijpeds.v5.i4.pp486-501.

[16] H. Attia, "Fuzzy Logic Controller Effectiveness Evaluation through Comparative Memberships for Photovoltaic Maximum Power Point Tracking Function," International Journal of Power Electronics and Drive Systems (IJPEDS), vol. 9, no. 3, pp. 1147-1156, 2018, doi: 10.11591/ijpeds.v9.i3.pp1147-1156.

[17] F. A. O. Aashoor, "Maximum power point tracking techniques for photovoltaic water pumping system," Ph.D. dissertation, Dept. Elect. Elect. Eng., Univ. of Bath, Claverton Down, UK, 2015.

[18] D. Mathur, "Maximum Power Point Tracking with Artificial Neural Network," International Journal of Emerging Science and Engineering (IJESE), vol. 2, no. 3, 2014, doi: 10.1155/2012/506709.

[19] R. Haque, "Transmission loss allocation using artificial neural networks," Master Thesis, University of Saskatchewan Saskatoon, Saskatoon, Canada, 2006.

[20] N. Kalaiarasi, S. Paramasivam, and S. Kundu, "Control of Z-Source Inverter Based PV System with MPPT Using ANFIS," International Review on Modelling and Simulations (IREMOS), vol. 7, no. 5, pp. 797-806, 2014, doi: 10.15866/iremos.v7i5.1970.

[21] A. Ravi, J. Shameema Sulthana, R. Satheesh, and R. Aandal, "Conventional maximum power point tracking techniques for solar photovoltaic systems a concise review," Journal of Critical Reveiews, vol. 7, no. 6, pp. 8699, 2020

[22] A. Youcef, A. Miloudi, R. Sayah, and H. Sayah, "Optimization of partially shaded PV array using a modified PandO MPPT algorithm," Leonardo Electronic J. Practices and Technologies, vol. 15, no. 28, pp. 179-196, 2016.

[23] M. Hebchi, A. Kouzou, and A. Choucha, "A modified variable step size for Maximum Power Point tracking based on Perturb and observe algorithm," Electrotehnica, Electronica, Automatica (EEA), vol. 66, no. 4, pp. 5-14, 2018.

[24] Bahaa A. Numan, Amina M. Shakir, Anas L. Mahmood, "Photovoltaic array maximum power point tracking via modified perturbation and observation algorithm," International Journal of Power Electronics and Drive System (IJPEDS), vol.11, no.4, pp. 2007-2018, 2020, doi: 10.11591/ijpeds.v11.i4.pp2007-2018.

[25] Khadidja Saidi, Mountassar Maamoun, M'hamed Bounekhla, "A new high performance variable step size perturb and observe MPPT algorithm for photovoltaic system," International Journal of Power Electronics and Drive System (IJPEDS), vol. 10, no. 3, pp. 1662-1674, 2019, doi: 10.11591/ijpeds.v10.i3.pp1662-1674.

[26] V. KViswambaran, A. Bati, and E. Zhou, "Review of AI Based Maximum Power Point Tracking Techniques and Performance Evaluation of Artificial Neural Network based MPPT Controller for Photovoltaic Systems," International Journal of Advance Science and Technology, vol. 29, no. 10S, (2020), pp. 8159-8171.

[27] H. J. El-Khozondar, R. J. El-Khozondar, K. Matter, and T. Suntio, "A review study of photovoltaic array maximum power tracking algorithms," Renewables: Wind, Water, and Solar, vol. 3, no. 3, 2016, DOI 10.1186/s40807-016-0022-8. 